\title{
Iris Neoplasm
}

National Cancer Institute

\section{Source}

National Cancer Institute. Iris Neoplasm. NCI Thesaurus. Code C3142.

A neoplasm that affects the iris. This category includes nevus and melanoma. 